\title{
Der „Hegar-Test“ erleichtert das Auffinden eines dystopen suburethralen Bandes
}

Häufig ist das intraoperative Lokalisieren eines dystopen, obstruktiv wirkenden oder in die Harnröhre arrodierten TVT- oder TOT-Bandes schwierig. Hier hat sich ein einfacher Trick bewährt, um aufwendige, teilweise traumatisierende Präparationen zu vermeiden.

Meist gelingt die ungefähre Ortung des TVT- oder TOT-Bandes mit der IntroitusSonografie. Bei der Freilegung vor der Banddurchtrennung oder-resektion ist es jedoch oft schwierig, Kontakt zum Band herzustellen. Um die Palpation zu erleichtern, wird die Harnröhre mit einem Hegarstift armiert und nach kontralateral und kaudal angespannt: zur Lokalisation des rechten Schenkels nach 5 Uhr bzw. des linken Schenkels nach 7 Uhr. Der palpierende Finger der anderen Hand kann nun im „Spiel“ des Hegar-Stiftes zwischen „locker" und „gespannt“ das Band als derbe, querverlaufende Struktur tasten. Ggf. gelingt es sogar, das Band derart angespannt ohne Freipräparation mit einem Messer durch die Vaginalwand zu durchtrennen. Der Erfolg lässt sich sofort mit dem „Hegar-Test“" kontrollieren: Wurde das Band komplett durchtrennt, kann es nicht mehr getastet werden.

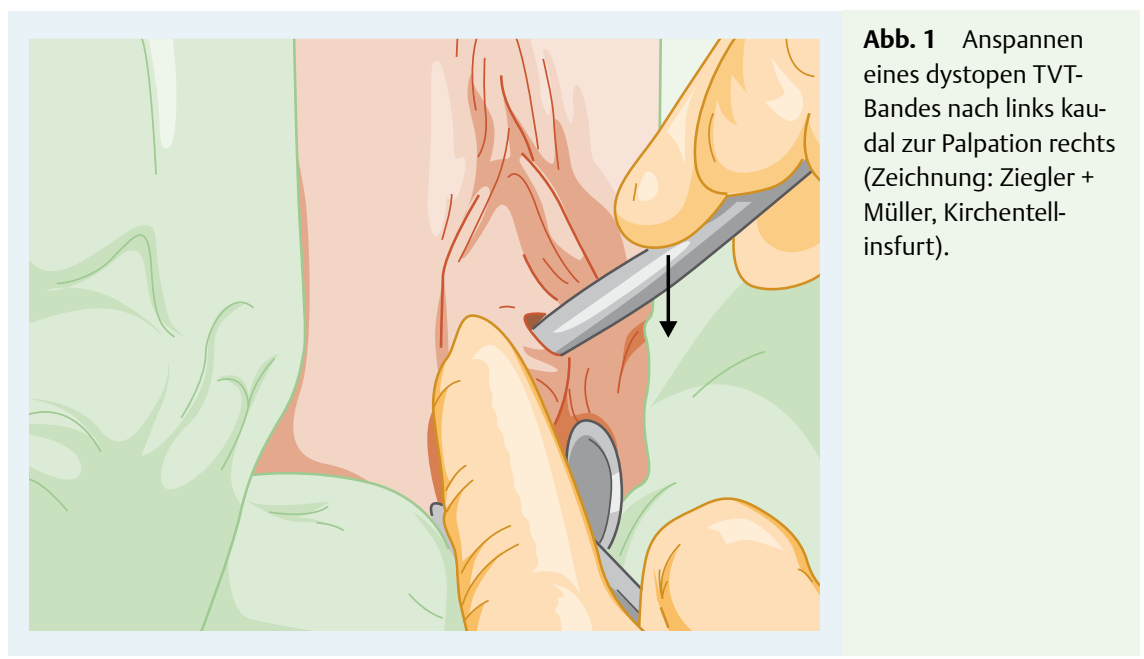

Dr. Andreas Wiedemann, Witten Dr. Jacek Kociszewski, Hagen
Korrespondenz:

Dr. Andreas Wiedemann

Evangelisches Krankenhaus im Diakoniewerk Ruhr gGmbH, Lehrstuhl für Geriatrie der Universität Witten/Herdecke

Pferdebachstr. 27

58455 Witten

Tel. 02302/175-2521

Fax. 02302/175-2075

awiedemann@diakonie-ruhr.de 